\title{
ELECTRICAL PROPERTIES OF FINFET STRUCTURES
}

\author{
T. E. Rudenko ${ }^{1}$, V. I. Kilchytska ${ }^{1,2}$, N. Collaert $^{3}$, M. Jurczak ${ }^{3}$, \\ A. N. Nazarov', V. S. Lysenko ${ }^{1}$, and D. Flandre ${ }^{2}$ \\ ${ }^{1}$ Institute of Semiconductor Physics, NAS of Ukraine, Prospect Nauki 45, 03028 Kyiv, Ukraine \\ E-mail:tamara@lab15.kiev.ua \\ ${ }^{2}$ Laboratoire de Microйlectronique, Universitй catholique de Louvain, \\ Place du Levant 3, 1348 Louvain-la-Neuve, Belgium \\ ${ }^{3}$ InterUniversity Microelectronics Center (IMEC), Kapeldreef 75, 3001 Leuven, Belgium
}

\begin{abstract}
ELECTRICAL PROPERTIES OF FINFET STRUCTURES

T. E. Rudenko, V. I. Kilchytska, N. Collaert, M. Jurczak, A. N. Nazarov, V. S. Lysenko, and D. Flandre
\end{abstract}

Electrical properties of FinFET (fin field-effect-transistor) structures are investigated. These structures are considered to be the most promising candidates for the creation of nano-scale metal-oxidesemiconductor (MOS) devices and integrated circuits due to strong suppression of the short-channel effects. The impact of the structure dimensions on the characteristics of the transistors is studied. Particular attention is given to the carrier mobility in the inversion channel of FinFET structures.

Key words: Metal-oxide-semiconductor (MOS) transistor; semiconductor on insulator (SOI); nano-scale devices; FinFET (fin field-effect-transistor).

\section{Анотація}

\section{ЕЛЕКТРИЧНІ ВЛАСТИВОСТІ FINFЕТ СТРУКТУР}

Т. О. Руденко, В. І. Кільчицька, Н. Коллаерт, М. Юрчак, О. М. Назаров, В. С. Лисенко, Д. Фландр

Досліджено електричні властивості транзисторних структур типу FinFET (fin field-effecttransistor). Ці структури вважаються найбільш перспективними для створення нано-розмірних метал-оксид-напівпровідник (МОН) транзисторів і інтегральних схем завдяки значному послабленню коротко-канальних ефектів. Досліджено вплив геометричних розмірів структури на характеристики транзисторів. Особливу увагу приділено рухливості носіїв в інверсійному каналі FinFET структур.

Ключові слова: Метал-оксид-напівпровідник (МОН) транзистор; кремній на ізоляторі (KHI); нано-розмірні прилади; FinFET (fin field-effect-transistor). 


\section{Аннотация}

\section{ЭЛЕКТРИЧЕСКИЕ СВОЙСТВА FINFЕТ СТРУКТУР}

\section{Т. Е. Руденко, В. И. Кильчицкая, Н. Коллаерт, М. Юрчак, А. Н. Назаров, В. С. Лысенко, Д. Фландр}

Исследованы электрические свойства транзисторных структур типа FinFET (fin fieldeffect-transistor). Эти структуры считаются наиболее перспективными для создания наноразмерных металл-окисел-полупроводник (МОП) транзисторов и интегральных схем благодаря сильному подавлению коротко-канальных эффектов. Исследовано влияние геометрических размеров структуры на характеристики транзисторов. Особое внимание уделено подвижности носителей в инверсионном канале FinFET структур.

Ключевые слова: Металл-окисел-полупроводник (МОП) транзистор; кремний на изоляторе; нано-размерные приборы; FinFET (fin field-effect-transistor).

\section{Introduction}

Scaling of CMOS into nano-meter region led to the development of new device structures. Suitable candidates are silicon-on-insulator (SOI) devices with multiple gates such as double-gate, triplegate, Omega-gate, gate-all-around FET structures, which can be scaled more aggressively than conventional planar bulk-Si devices. The key feature of all these multi-gate SOI MOSFETs is strong gate control of the channel region due to the thin Si bodies, effectively suppressing short-channel effects, even without using high channel doping. Amongst different multi-gate structures, the FinFET is considered to be the most promising candidate for future nano-scaled devices because of its excellent scalability, along with relatively simple fabrication [1][3]. Therefore electrical characteristics of FinFETs are of great interest.

In this work, the electrical characteristics of the advanced FinFET structures with high- $K$ gate dielectrics and mid-gap gate electrodes are studied, focusing on the FinFET mobility. Due to a three-dimensional device nature and location of the top and lateral channels in different crystallographic planes, the mobility behaviour in FinFETs can be different from that in single-gate and double-gate devices. In a given work, for better understanding of the FinFET mobility, we study the effective mobility in narrow-fin devices versus quasi-planar (very wide-fin) devices, and as a function of the fin width (down to $25 \mathrm{~nm}$ ).

\section{Device description}

The devices studied were processed at IMEC. The triple-gate FinFETs with $\Omega$-configuration and metal gate electrodes were fabricated on SOI wa- fers featuring a $65 \mathrm{~nm}$-thick Si film on $145-\mathrm{nm}$ of buried oxide. Details of fabrication processes are described in [4]. The gate covered three sides of the fin, as shown in Fig. 1, creating a channel on each side: the top channel and the two lateral channels, lying, respectively, in (100) and (110) crystallographic planes.

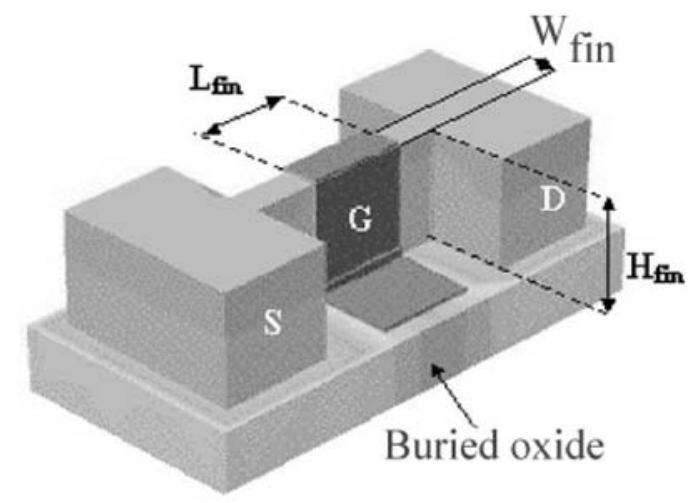

Fig. 1. Schematic representation of the FinFET architecture.

In this study, the devices with different gate stacks were used. In one of them, the gate stack consisted of a plasma nitrided oxide ( $\mathrm{SiON})$ with $1.8 \mathrm{~nm}$ equivalent oxide thickness of and chemical vapor deposited (CVD) $\mathrm{TiN}$, as a gate electrode. The devices studied were $n$ - and $\mathrm{p}$-channel 5 -fin FETs with a fin height $H_{\text {fin }}=60 \mathrm{~nm}$ and fin width $W_{\text {fin }}$ varying from $3 \mu \mathrm{m}$ down to $25 \mathrm{~nm}$. No channel doping was used in these devices. The SEM photographs of the top and cross section of the FinFETs with $W_{\text {fin }}=25 \mathrm{~nm}$ are shown in Fig. 2 .

Another set of the devices had an atomic layer deposited (ALD) TaN gate electrode and two types of gate dielectrics, namely, a nitrided oxide (SiON) with $1.8 \mathrm{~nm}$ equivalent oxide thickness and 
ALD $\mathrm{HfO}_{2}$ deposited on a chemical oxide with total equivalent oxide thickness of $1.6 \mathrm{~nm}$. The TaN gate devices received a channel implant to provide channel doping $\sim 10^{18} \mathrm{~cm}^{-3}$. The measured devices were multiple-fin FETs consisting of 30 fins with $H_{\text {fin }}=50 \mathrm{~nm}$ and $W_{\text {fin }}=45 \mathrm{~nm}$. Comparative measurements were performed on very wide single-fin $\left(W_{\text {fin }}=10 \mu \mathrm{m}\right)$ structures.

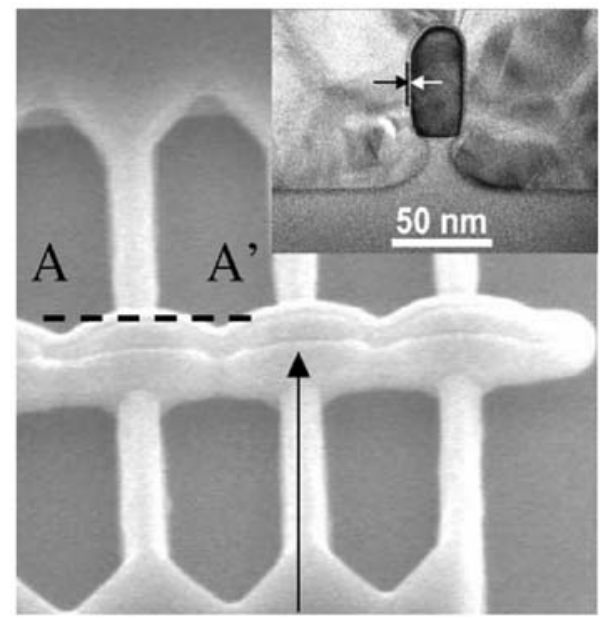

Fig. 2. The SEM photographs of the top and cross section of the FinFETs with $W_{f i n}=25 \mathrm{~nm}$.

In this study, devices with the gate length $L_{g}$ from $20 \mu \mathrm{m}$ down to $40 \mathrm{~nm}$ were measured. However, for mobility measurements only very long devices $\left(L_{g}=10-20 \mu \mathrm{m}\right)$ were used to avoid short-channel and series resistance effects. All measurements were performed at room temperature.

\section{Impact of the fin width on the short-channel effects}

The short-channel effects in a MOSFET are usually characterized by the threshold voltage $\left(V_{t h}\right)$ roll-off and degradation of subthreshold slope with shrinking the gate length. A key advantage of FinFETs is the reduction of the short-channel effects by decreasing the fin width without use of high channel doping. This is illustrated by Fig. 3 (a), showing the comparison of the subthreshold drain current $\left(I_{d}\right)$ versus gate voltage $\left(V_{g}\right)$ characteristics of the undoped very short $n$-channel devices $\left(L_{g}=80 \mathrm{~nm}\right)$ with different fin widths. The inset in Fig. 3 (a) shows the inverse subthreshold slope $S$ as a function of the fin width. A clear improvement of the subthreshold characteristics of the short-channel device is observed when $W_{\text {fin }}$ is reduced, namely: the subthreshold slope becomes steeper (i.e.,
$S$ decreases), the off-state current reduces, and $V_{\text {th }}$ increases, approaching its long-channel value. Fig. 3(b) shows degradation of the subthreshold characteristics in the narrow-fin devices $\left(W_{\text {fin }}=25\right.$ $\mathrm{nm})$ with decreasing the gate length from $1 \mu \mathrm{m}$ to $40 \mathrm{~nm}$. The inset in Fig. 3(b) shows the corresponding degradation of the subthreshold slope. From Fig. 3(b) it is seen that the behavior of the $I_{d}(V)$-characteristics of very narrow-fin devices (with $W_{\text {fin }}=25 \mathrm{~nm}$ ) remains the same as in longchannel devices, showing invariable $V_{\text {th }}$ and excellent $S=61-64 \mathrm{mV} /$ decade, when the gate length reduces down to $L_{g}=60 \mathrm{~nm}$. These measurements fully support theoretical predictions, which show that adequate suppression of the short-channel effects in a FinFET can be reached if the fin width is $\leq 2 / 3$ of the gate length [2], [3].
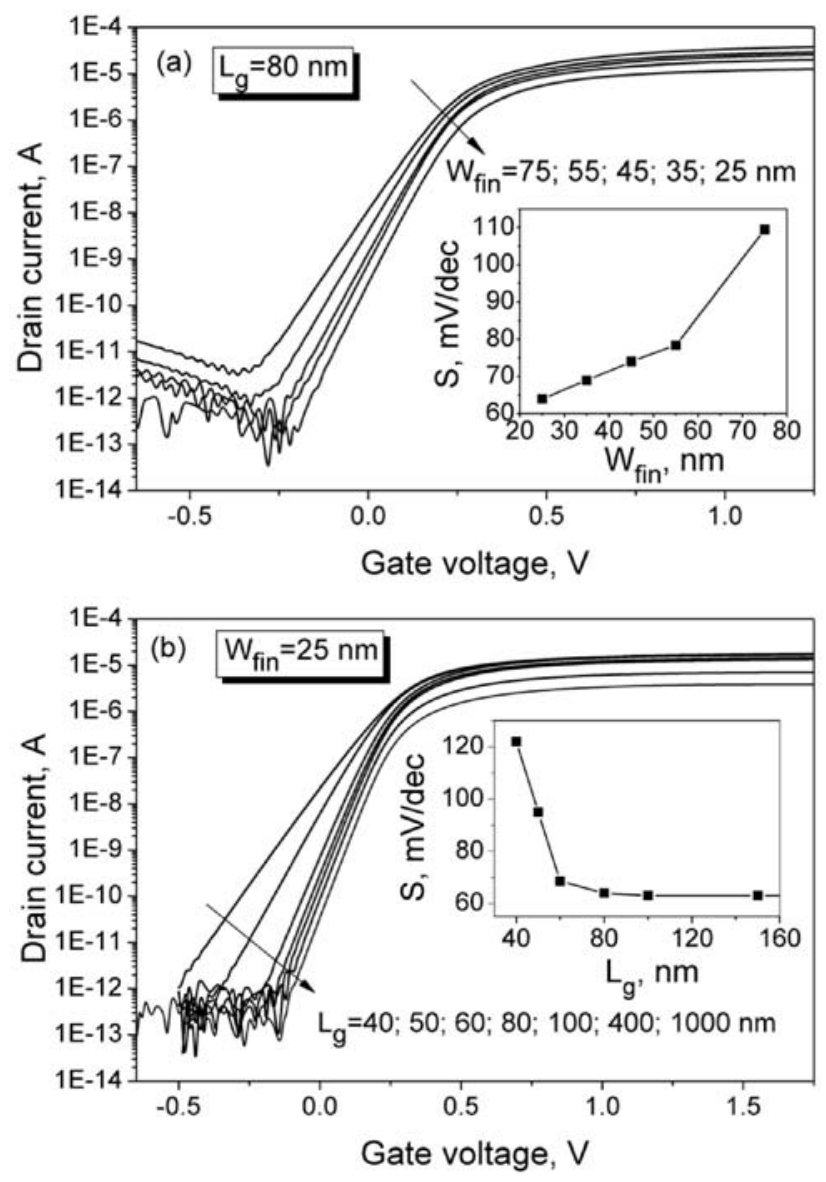

Fig. 3. Subthreshold characteristics of undoped n-channel FinFETs with: (a) $L=80 \mathrm{~nm}$ and different fin widths; (b) $W_{\text {fin }}=25 \mathrm{~nm}$ and different gate lengths. The inset in Fig. 3(a) shows the inverse subthreshold slope as a function of the fin width, and in Fig. 3(b) as a function of the gate length. Measurements are performed on 5-fin devices with the TiN/SiON gate stack. 


\section{Effective channel mobility}

\subsection{Factors affecting the FinFET mobility}

Amongst the factors which can affect the FinFET mobility, the different crystallographic orientation of the top and lateral channels is most important. The sidewall channels in FinFETs fabricated on a standard (100) wafer lie typically in a (110) plane. In a narrow-fin FET, in which the fin width is less than the fin height $\left(W_{f i n}<H_{f i n}\right)$, the conduction is mainly determined by side channels. Thus, due to anisotropy of the effective masses, hole mobility in FinFETs is expected to be enhanced, while electron mobility to be degraded compared to conventional planar devices with the (100) surface orientation. Besides, the effective mobility in FinFETs can be affected by volume inversion at low charge densities, fin roughness, and, in the case of doped channel, different doping levels of the fin top and sides.

\subsection{Mobility extraction procedure}

The effective mobility, $\mu_{\text {eff }}$, in a MOSFET is traditionally defined from the drain current $I_{d}$ measured at low drain voltage $V_{d}$, as follows:

$$
\mu_{\text {eff }}=\frac{I_{d}}{(W / L) \cdot V_{d} \cdot q \cdot N_{i n v}},
$$

where $W$ and $L$ are, respectively, channel width and length, $N_{i n v}$ is the inversion carrier density per unit gate area, $q$ is the electron charge. In this work, $N_{\text {inv }}$ was experimentally determined using a split $C$ $V$ technique, which is usually used for MOSFETs with ultra-thin gate dielectrics [5]. In a split $C-V$ technique, $N_{i n v}$ is determined from the measured gate-to-channel capacitance $C_{g c}$ and its normalizing to the gate area:

$$
N_{\text {inv }}=\frac{1}{q} \cdot \int_{V_{\text {acc }}}^{V_{g}} \frac{C_{g c}\left(V_{g}\right)}{W \cdot L} d V_{g},
$$

where $C_{g c}$ is the gate-to-channel capacitance per whole gate area, $V_{g}$ is the gate voltage, and $V_{\text {acc }}$ is the gate voltage in accumulation, where $N_{i n v}=0$. From Eqs.(1) and (2), $\mu_{e f f}$ can be obtained as:

$$
\mu_{e f f}\left(V_{g}\right)=\frac{L^{2} \cdot I_{d}}{V_{d} \cdot \int_{V_{a c c}}^{V_{g}} C_{g c}\left(V_{g}\right) d V_{g}} .
$$

From Eq. (3) it follows that with the split C-V measurements, $\mu_{e f f}(V)$ can be determined without knowledge of both the dielectric thickness and channel width, which is particularly important in the case of FinFETs, in which both are not reliably known. However, when plotting $\mu_{\text {eff }}$ as a function of $N_{i n v}$ it is neccessary to know the device channel width. In this work, the channel width in a FinFET was defined as: $W=$ number of fins $\times\left(2 H_{f i n}+W_{f i n}\right)$.

\subsection{Mobility in TaN gate FinFETs with doped- channel}

Fig. $4(a)$, (b) shows the effective hole $\left(\mu_{p}\right)$ and electron $\left(\mu_{n}\right)$ mobilities as a function of the inversion carrier density obtained in $\mathrm{TaN}$ gate narrow-fin devices $\left(W_{f i n}=45 \mathrm{~nm}\right)$ and quasi-planar very widefin devices $\left(W_{f i n}=10 \mu \mathrm{m}\right)$ with highly-doped channel and two types of the gate dielectrics. It is evident from Fig. 4(a) that for both $\mathrm{SiON}$ and $\mathrm{HfO}_{2}$ gate dielectrics, $\mu_{p}$ in narrow-fin devices determined mainly by (110)-oriented fin sidewalls is significantly higher ( 2.5 times) than that in counterpart quasi-planar (very wide-fin) devices, determined by the (100) top channel mobility, as expected due to anisotropy of the effective masses. For the same reason, one might expect that electron mobility in narrow FinFETs to be degraded compared to that in quasi-planar devices. However, as is seen from Fig. 4 (b), contrary to expectations, at moderate and low $N_{i n v}$, the effective $\mu_{n}$ in narrow FinFETs with highly doped channel is also much higher than in their counterpart quasiplanar devices. This enhancement of $\mu_{n}$ in narrow FinFETs, which reaches factor of 3 at low $N_{i n v}$ and vanishes at high $N_{i n v}$, is attributed to lower doping of the fin sidewalls compared to the fin top, resulting in the lower Coulomb scattering and lower transverse electric field $E_{\text {eff }}$, as well as to fully-depleted doublegate-like operation of narrow FinFETs, also reducing $E_{\text {eff }}$ These two factors improve also hole mobility at low $N_{i n v}$. Such behavior observed for both metal gate devices [6] and poly-Si gate devices [7].

\subsection{Mobility in undoped-channel FinFETs with TiN gate and various fin widths}

Fig. 5 presents $\mu_{p}$ and $\mu_{n}$ as a function of $N_{i n v}$ in undoped-channel FETs with various $W_{f i n}$. For undoped channel, the enhancement of $\mu_{p}$ and degradation of $\mu_{n}$, in narrow FinFETs are observed, as compared to quasi-planar wide-fin devices, which can be attributed to surface orientation effect of the top and lateral channels. The behavior of the FinFET mobility in respect to the fin width is different in different regions of $N_{i n v}$. In the high $N_{i n v}$ region, where $N_{i n v}>6 \times 10^{12} \mathrm{~cm}^{-2}$, the fin width dependence of both $\mu_{p}$ and $\mu_{n}$ with $W_{f i n}$ can be attributed to variation 
of the relative contributions of top and lateral conduction channels, having different mobilities due to different surface orientation. In this high $N_{i n v}$ region, the FinFET mobility is presumably controlled by the surface roughness scattering. However, at lower $N_{i n v}$, the $\mu_{n}$ behavior in a FinFET is more complicated, that is, the conduction of the device cannot be presented simply as a sum of the top and lateral conduction channels. It is assumed that in the $N_{i n v}$ range of the maximum $\mu_{n}$ in FinFETs (where $\mu_{n}$ slightly increases with decreasing $W_{\text {fin }}$ from $75 \mathrm{~nm}$ to $25 \mathrm{~nm}$ ), $\mu_{n}$ is governed mainly by phonon scattering, while at lower $N_{i n v}$ where $\mu_{n}$ strongly decreases with decreasing $N_{i n v}$ and $W_{f i n}$, the dominant scattering mechanism is Coulomb scattering. A stronger degradation of $\mu_{n}$ with decreasing $W_{\text {fin }}$ at low $N_{i n,}$ as compared to the predicted and measured degradation in ultra-thin body and double-gate SOI devices for the same body thickness range [8], might be attributed to the fact that in tri-gate FinFETs, carriers can be simultaneously affected by four $\mathrm{Si}-\mathrm{SiO}_{2}$ interfaces.
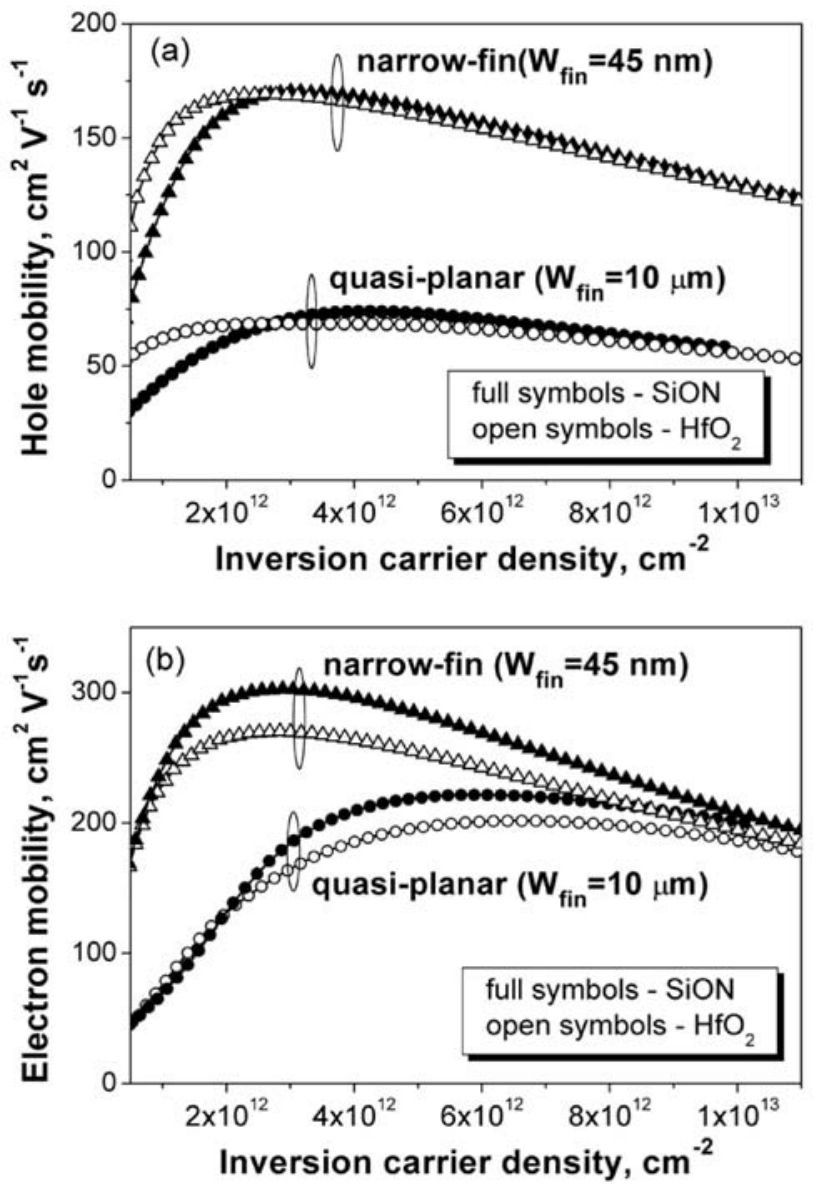

Fig. 4. The effective hole (a) and electron (b) mobility in TaN gate narrow-fin devices $\left(W_{\text {fin }}=45 \mathrm{~nm}\right)$ and quasiplanar very wide-fin devices $\left(W_{\text {fin }}^{\text {fin }}=10 \mu \mathrm{m}\right)$ with highly doped channel plotted as a function of the inversion carrier density.
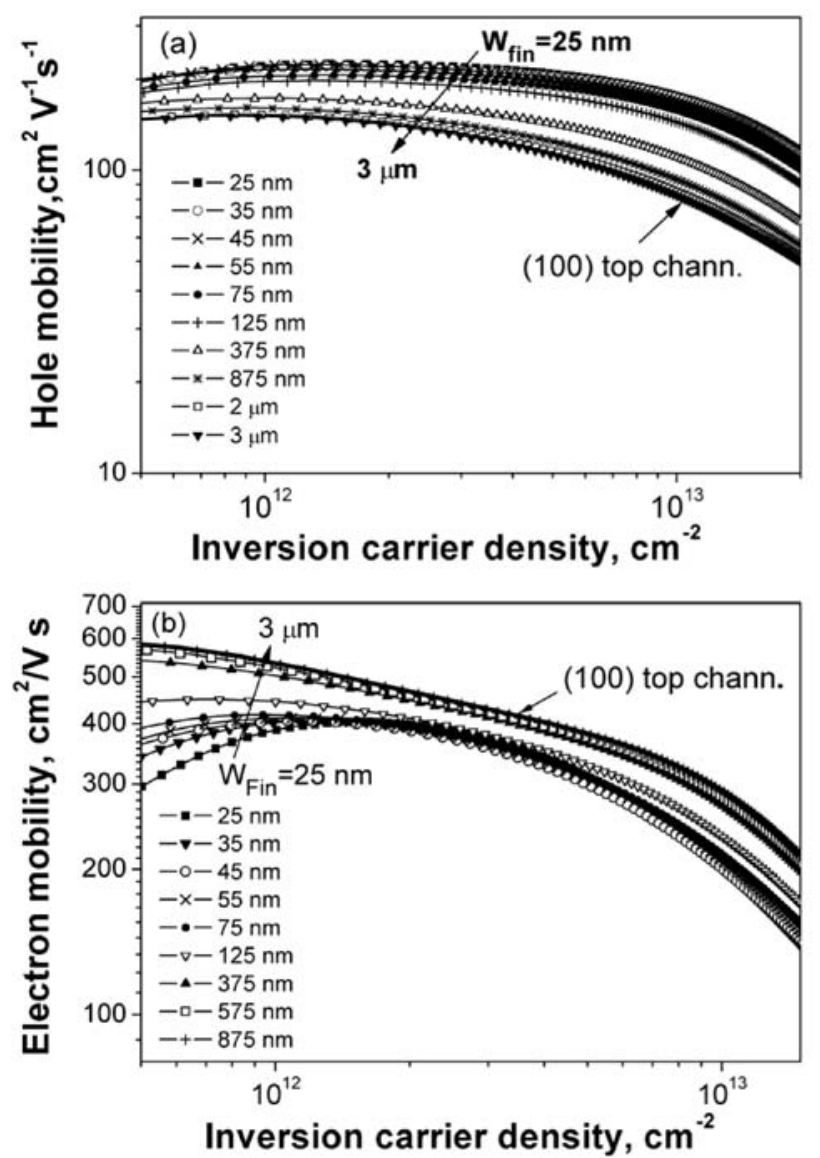

Fig. 5. The effective hole (a) and electron (b) mobilities in undoped-channel devices with various $W_{\text {fin }}(\mathrm{TiN} /$ $\left.\mathrm{SiON}, H_{\text {fin }}=60 \mathrm{~nm}, L_{g}=10 \mu \mathrm{m}\right)$.

\section{Conclusions}

The behavior of the effective mobility in narrow FinFET structures was studied as compared to quasi-planar very wide-fin structures, and as a function of the fin width. It is found that dopedchannel narrow FinFET structures reveal a strong enhancement of hole mobility (more than twice) in narrow FinFET devices compared to their counterpart quasi-planar very wide-fin devices, as expected due to a (110) orientation of fin sidewalls, and also surprising enhancement of electron mobility, attributed to lower doping of fin sides and fully-depleted double-gate-like operation of narrow FinFETs, resulting in lower Coulomb scattering and lower effective electric field.

Undoped-channel narrow FinFETs exhibit higher hole mobility and lower electron mobility, as compared to those in quasi-planar (very wide-fin) SOI devices, which has been attributed to different surface orientation of the fin top and sides. At high 
inversion carrier densities, impact of the fin width on the effective mobility in a triple-gate FinFET has been explained by the variations of the relative contributions of top and lateral conduction channels. A strong decrease in the electron mobility with reducing the fin width observed at low carrier densities has been explained by Coulomb scattering, enhanced due to interaction with four $\mathrm{Si}_{-} \mathrm{SiO}_{2}$ interfaces.

\section{Acknowledgements}

This work has been partly funded by the European Commission under the frame of the Network of Excellence "SINANO" (Silicon-based Nanodevices, IST-506844). T. Rudenko thanks "SINANO" for the special personal exchange grant.

\section{References}

1. Hisamoto D., Lee W. - C, Kedzierski J., Takeuchi H., Asano K., Kuo C., Anderson E., King T. - J., Bokor J., and. Hu C. FinFET - A self-aligned double-gate MOSFET scalable to $20 \mathrm{~nm} / /$ IEEE Trans. Electron Devices. - 2000. - Vol. 47. - P. 2320-2325.

2. Park J. - T., Colinge J. - P. Multi-gate SOI MOSFETs: Device design guidelines // IEEE Trans. Electron Devices. - 2002. - Vol. 49. - P. 2222-2229.
3. Yu B., Chang L., Ahmed S., Wang H., Bell S., Yang C. - Y., Tabery C., Ho C., Xiang Q., King T. - J., Bokor J., Hu C., Lin M. - R., and Kyser D. FinFET scaling to $10 \mathrm{~nm}$ gate length // IEDM Tech. Dig. 2002. - P. 251-254.

4. Collaert N. et al. Tall triple-gate device with TiN/ $\mathrm{HfO}_{2}$ gate stack // Symposium on VLSI Technology. - 2005. - P. 108-109.

5. Romanjek K., Andrieu F., Ernst T., and Ghibaudo G. Improved split $\mathrm{C}-\mathrm{V}$ method for effective mobility extraction in sub-0.1- $\mu \mathrm{m}$ Si MOSFETs // IEEE Electron Device Letters. - 2004. - Vol. 25. - P. 583585.

6. Rudenko T., Collaert N., Gendt S. De, Kilchytska V., Jurczak M., and Flandre D. Effective mobility in FinFET structures with $\mathrm{HfO}_{2}$ and $\mathrm{SiON}$ gate dielectrics and TaN gate electrode // Microelectronic Engineering. -2005 . - Vol. 80. - P. 386-389.

7. Rudenko T., Kilchytska V., Collaert N., Gendt S. De, Rooyackers R., Jurczak M., Flandre D. Specific features of the capacitance and mobility behaviors in FinFET structures // Proc. ESSDERC 2005 Conference - Grenoble (France) -2005. - P. 8588.

8. Esseni D., Mastrapasqua M., Celler G.K.,. Baumann F.H, Fiegna C., Selmi L. and Sangiorgi E. Low field mobility of ultra-thin SOI $n$ - and p-MOSFETs: Measurements and implications on the performance of ultra-short MOSFETs // IEDM Tech. Dig. 2001. - P. 671-674. 